\title{
Bereavement during the Covid-19 pandemic in the UK: What do we know so far?
}

Emily Harrop Cardiff University, Marie Curie Palliative Care Research Centre, Division of Population Medicine

Lucy E Selman University of Bristol, Palliative and End of Life Care Research Group, Population Health Sciences, Bristol Medical School

Keywords: bereavement, grief, pandemics, coronavirus infections, bereavement services

\section{Implications for practice}

- Improve communication with families at the end of life, enabling visiting and contact with patients as far as possible and providing better support immediately after a death. This postdeath contact should include information-giving on bereavement services and opportunities to discuss the death/patient-care.

- Greater resourcing and expansion of national and regional adult and child bereavement services, with strategies to improve awareness of bereavement support options for adults and children and young people. Information on services and self-help resources should be widely available in online and community settings.

- Community, school and work-based based interventions/guidance should strengthen supportive networks and improve grief literacy, compassion and communication skills across society. When lockdown restrictions are in place, more flexible support bubbles should be permitted for the recently bereaved.

- Provide opportunities for remembrance, greater respect and listening to those bereaved, including national and local initiatives which support private and public remembrance; and inclusive consultation with those recently bereaved (eg via the UK Commission on Bereavement: bereavementcommission.org.uk)

\section{Abstract}

The Covid-19 pandemic has been a devastating mass bereavement event, with measures to control the virus leading to unprecedented changes to end-of-life and mourning practices. In this review we consider the research evidence on the experiences of people bereaved during the pandemic. We summarise key findings reported in the first five publications from our UK-based Bereavement during COVID-19 study, drawing comparisons with available evidence from other studies of bereavement during the pandemic. We summarise these findings across three main topics: experiences at the end of life and in early bereavement; coping and informal support during the pandemic; and access to bereavement and mental health services. The synthesis demonstrates the exceptional challenges of pandemic bereavement, including high levels of disruption to end-of-life care, dying and mourning practices as well as to people's social networks and usual coping mechanisms. We identified considerable needs for emotional, therapeutic and informal support among bereaved people, compounded by significant difficulties in receiving and accessing such support. We provide evidence-based recommendations for improving people's experiences of bereavement and access to support at all levels. 
As we approach the second anniversary of the first Covid-19 reported deaths in the UK, we consider the growing body of research evidence on the experiences of people bereaved during this most devastating and disruptive of global pandemics. We summarise key findings reported in the first five publications from our UK-based Bereavement during Covid-19 study, drawing comparisons with available evidence from other studies investigating the experiences of bereaved people during Covid-19.

The Bereavement during COVID-19 study includes a mixed-methods longitudinal survey investigating end-of-life experiences (including experiences of care before and immediately after the death), bereavement support needs and experiences in the UK during Covid-19. Baseline data was collected from people bereaved in the UK from 16 March 2020 (of any cause of death), when the first infection control restrictions were implemented, until 2 January 2021. The survey was open from 28 August 2020 to 5 January 2021 and was completed by 711 adults who had been bereaved between 1 and 279 days ago (median 152 days (5 months)).

The study publications summarised here report on interim (Harrop et al, 2020) and full results from the baseline survey (Harrop et al, 2021a; 2021b; Selman et al, 2021a; Torrens-Burton et al, 2021). We also include in the summary a publication reporting results from the second round survey responses of 104 parent/guardian participants, who answered a question on the support experiences and needs of their children, aged 25 or under (Harrop et al, 2021b).

Here we summarise study findings to date in three main topics: experiences at the end of life and in early bereavement; coping and informal support during the pandemic; and access to bereavement and mental health services.

\section{Sample characteristics}

Participant characteristics are presented in Table 1. Participants represented diverse geographical areas, deprivation indexes and levels of education. $88.6 \%$ of participants were female $(n=628)$; the mean age of the bereaved person was 49.5 years old ( $\mathrm{SD}=12.9$; range 18-90). The most common relationship of the deceased to the bereaved was parent $(\mathrm{n}=395,55.6 \%)$, followed by partner/spouse $(\mathrm{n}=152,21.4 \%) .72$ people $(10.1 \%)$ had experienced more than one bereavement since 16 March 2020. 33 people $(4.7 \%)$ self-identified as from a minority ethnic background. The mean age of the deceased person was 72.2 years old ( $\mathrm{SD}=16.1$; range during pregnancy to 102 years) (Table 2). 43.8\% ( $\mathrm{n}=311)$ died of confirmed/ suspected Covid-19, 21.9\% ( $\mathrm{n}=156)$ from cancer, and $16.7 \%(\mathrm{n}=119)$ from another life-limiting condition. Most died in hospital $(\mathrm{n}=410 ; 57.8 \%)$.

\section{Experiences at the end of life and in early bereavement}

We found almost all participants were affected by the restrictions placed on family visiting in health and care settings, funerals and everyday social interaction. These included restricted funerals $(93 \%)$, limited contact with other close relatives or friends $(80 \%)$, loneliness and social isolation $(67 \%)$ and being 'unable to say goodbye as I would have liked' $(64 \%)$. There was wide variation in overall reported experiences of end-of-life care; for example, while $21.8 \%$ reported they were always involved in decision about the care of their loved one, $21.8 \%$ reported that they were never involved; $32.3 \%$ reported that they were fully informed about the approaching death while $17.7 \%$ said they were not at all informed (Selman et al, 2021a). Lack of support following the death was a major issue, with $35.4 \%$ of participants reporting that they felt 'not at all' supported by professionals immediately after the death. Similar problems have been reported in pandemic bereavement studies conducted in the Netherlands, UK and USA (Becque et al, 2021; Hanna et al, 2021; Mayland et al; 2021; Neimeyer \& Lee, 2021). Problems communicating with healthcare providers (HPCs) related to difficulty getting information about their family member, being misinformed about their condition and hospital policies and not being involved in care or treatment decisions (Harrop et al, 2020; Torrens-Burton et al, 2021). More positive experiences included being treated with compassion and kindness, being able to visit, and relatives feeling that they were kept well-informed about their family member's condition and care (Harrop et al, 2020). Again, these findings are consistent with results from Dutch and UK studies (Becque et al, 2021; Hanna et al, 2021; Mayland et al, 2021).

We identified several risk factors for problematic experiences towards the end of life and in early bereavement including place of death and whether the death was expected or not (Selman et al, 2021 a). Deaths in hospital/care home compared 
Table 1: Characteristics of the bereaved person

$\begin{array}{lccc}\text { Age } & \text { Mean [median] } & \text { SD } & \text { Min-max } \\ \text { Age (years) } & 49.5[50.0] & 12.9 & 18-90 \\ \text { Gender identity } & \mathbf{n} & \text { Percentage } & \\ \text { Male } & 74 & 10.4 \% & \\ \text { Female } & 628 & 88.6 \% & \\ \text { Other } & 7 & 1.0 \% & \end{array}$

\section{Ethnicity}

$\begin{array}{lcc}\text { Non-BAME (total) } & 676 & 95.3 \% \\ \text { White British } & 438 & 64.8 \% \\ \text { White English } & 111 & 16.4 \% \\ \text { White Welsh } & 41 & 6.1 \% \\ \text { Northern Irish } & 22 & 3.3 \% \\ \text { White Scottish } & 40 & 5.9 \% \\ \text { Any other white } & 17 & 2.5 \% \\ \text { White Irish } & 7 & 1.0 \% \\ \text { BAME (total) } & 33 & 4.7 \% \\ \text { White and Black Caribbean } & 12 & 36.4 \% \\ \text { White and Asian } & 5 & 15.2 \% \\ \text { Indian } & 4 & 12.1 \% \\ \text { Black Caribbean } & 4 & 12.1 \% \\ \text { Any other mixed background } & 3 & 9.1 \% \\ \text { Pakistani } & 1 & 3.0 \% \\ \text { Bangladeshi } & 1 & 3.0 \% \\ \text { Arab } & 1 & 3.0 \% \\ \text { White and Black African } & 1 & 3.0 \% \\ \text { Any other Asian } & 1 & 3.0 \%\end{array}$

\section{Religious beliefs}

$\begin{array}{lcc}\text { Buddhism } & 8 & 1.2 \% \\ \text { Christian } & 251 & 36.7 \% \\ \text { Hinduism } & 3 & 0.4 \% \\ \text { Islam } & 5 & 0.7 \% \\ \text { Judaism } & 6 & 0.9 \% \\ \text { Sikhism } & 2 & 0.3 \% \\ \text { Other or agnostic } & 107 & 15.7 \% \\ \text { No } & 301 & 44.1 \%\end{array}$

\section{Highest qualification}

None or GCSES $\quad 108 \quad 15.3 \%$

A-level or apprenticeship or ONC $\quad 132 \quad 18.6 \%$

HND or university degree $\quad 468 \quad 66.1 \%$

\section{Region}

$\begin{array}{lcc}\text { England } & 517 & 78.5 \% \\ \text { Wales } & 63 & 9.6 \% \\ \text { Scotland } & 53 & 8.0 \% \\ \text { Northern Ireland } & 26 & 3.9 \%\end{array}$


Table 1: Characteristics of the bereaved person (cont)

Unemployed during the pandemic?

$\begin{array}{lcc}\text { Yes } & 55 & 7.9 \% \\ \text { No } & 645 & 92.1 \%\end{array}$

\section{Bereavements in previous year?}

$\begin{array}{lll}\text { Yes } & 158 & 22.5 \% \\ \text { No } & 543 & 77.5 \%\end{array}$

\section{IMD decile (England only) $(n=517)$}

2

3

4

5

6

7

8

9

10

\section{6}

45

49

52

64

52

58

57

46

50
$77.5 \%$

Key: $B A M E=$ Black, Asian or minority ethnic background; GCSE = General Certificate of Secondary Education for 15 and 16 year olds in the UK; A Levels = Advanced Level subject-based qualification for students in the UK aged 16 and above; ONC = Ordinary National Certificate (equivalent to A Levels); HND = Higher National Diploma (vocational qualification provided by higher or further education colleges in the UK); IMD = indices of multiple deprivation

with in hospice/at home increased the likelihood of the bereaved person being unable to visit prior to death or say goodbye as they wanted. By contrast, deaths that occurred in hospice/at home, and deaths that were expected increased the likelihood of the bereaved person being involved in care decisions and feeling well supported by healthcare professionals after the death. Bereavement due to Covid-19, compared with all other types of deaths, decreased the likelihood of being involved in care decisions and of feeling well supported by HCPs after the death, while increasing the likelihood of being unable to say goodbye (Selman et al, 2021a).

Our qualitative results demonstrate the emotional and psychological impacts of these experiences (Torrens-Burton et al, 2021). People described the distress and guilt caused by being unable to say goodbye and provide comfort to their dying relative, as observed in the other UK study (Hanna et al, 2021; Mayland et al, 2021). Parents also described the added confusion and upset caused to their children by being separated from grandparents before the death (Harrop et al, 2021b).
Having unanswered questions, regrets and doubts made it harder to process and reconcile their feelings surrounding the death (Torrens-Burton $e t$ al, 2021). Reflecting these difficulties, $60 \%$ of participants reported experiencing high or fairly high needs for help 'dealing with my feelings about the way my loved one died' (Harrop et al, 2021 a). Restricted funeral and memorialisation practices, inability to support one another and mourn collectively also made it difficult to find closure and begin to grieve (Torrens-Burton et al, 2021). These grief difficulties are consistent with the quantitative findings of a US pandemic study, that 'disrupted meaning' contributed to worse grief outcomes, and that higher levels of functional impairment occurred for all deaths during Covid19 compared with pre-pandemic times (Menzies et al, 2020; Breen et al, 2021).

\section{Coping and informal support during the pandemic}

Participants described the overwhelming and dehumanising effect of being bereaved at a time of 
Table 2: Characteristics of the deceased

$\begin{array}{lccc}\text { Age } & \text { Mean [median] } & \text { SD } & \text { Min-max } \\ \text { Age (years) } & 72.2[74.0] & 16.1 & 0-102\end{array}$

\section{Relationship of the deceased person to the bereaved*}

$\begin{array}{lcc}\text { Partner } & 152 & 21.4 \% \\ \text { (Male/female) } & (129 / 23) & (18.1 \% / 3.2 \%) \\ \text { Parent } & 395 & 55.6 \% \\ \text { (Father/mother) } & (218 / 197) & (30.7 \% / 27.7 \%) \\ \text { Grandparent } & 54 & 7.6 \% \\ \text { Sibling } & 23 & 3.2 \% \\ \text { (Brother/sister) } & (15 / 10) & (2.1 \%, 7.4 \%) \\ \text { Child } & 15 & 2.1 \% \\ \text { (Son/daughter) } & (12 / 4) & (1.7 \% / 0.6 \%) \\ \text { Other family member } & 46 & 6.5 \% \\ \text { Colleague or friend } & 26 & 3.7 \%\end{array}$

\section{Cause of death}

$\begin{array}{lcc}\text { Covid } & 273 & 38.5 \% \\ \text { Suspected Covid } & 38 & 5.4 \% \\ \text { Non-covid (total) } & 399 & 56.2 \% \\ \text { Cancer } & 156 & 21.9 \% \\ \text { Other PLLC** } & 118 & 16.7 \% \\ \text { Non-PLLC/SD*** } & 112 & 15.8 \% \\ \text { Don't know } & 12 & 3.0 \% \\ \text { Not specified } & 1 & 0.2 \%\end{array}$

\section{Was the death expected?}

$\begin{array}{lcc}\text { Yes } & 113 & 16.0 \% \\ \text { No } & 552 & 78.0 \% \\ \text { Don't know } & 43 & 6.1 \%\end{array}$

\section{Place of death}

$\begin{array}{lcc}\text { In hospital } & 410 & 57.7 \% \\ \text { In their home } & 158 & 22.2 \% \\ \text { In a hospice } & 37 & 5.2 \% \\ \text { In a care home } & 91 & 12.8 \% \\ \text { Other/Don't know } & 13 & 1.8 \%\end{array}$

* Multiple bereavements recorded by participants explain discrepancies between overall totals in sibling, child and parent groups and their sub-categories.

** PLLC = Progressive life-limiting condition e.g. heart disease, COPD, dementia

*** Non-PLLC/SD = Non-progressive life-limiting condition/sudden death eg stroke, heart attack, accident, suicide 
mass bereavement, with one in ten experiencing multiple deaths. This was exacerbated by insensitive and prolonged reporting of death statistics and other negative media coverage (Torrens-Burton et al, 2021), observed also in analyses of UK media coverage during the pandemic (Selman et al, 2021b; Sowden et al, 2021). People found it harder to openly grieve, and experienced anger and alienation in response to perceived government incompetence, conspiracy theories questioning the pandemic, and public disregard of social-distancing requirements and regulations (Torrens-Burton et al, 2021). Similar observations were reported in an analysis of Twitter data from bereaved family members and friends (Selman et al, 2021c) and another UK survey of bereaved people conducted early in the pandemic (Sue Ryder, 2020). Adding to this upset, many people described the further stress and distress that they encountered as they tried to organise the affairs of their deceased relative, particularly amidst the organisational chaos of lockdown (Torrens-Burton et al, 2021). Around a quarter of participants reported high/fairly high needs for help with administrative tasks and accessing financial and legal information and advice (Harrop et al, 2021a).

When lockdown restrictions were in place, people struggled with not being able to visit friends, engage in social and recreational activities and experience respite from their situation. Fear of catching or spreading Covid-19 also affected people's ability to cope and go about their daily lives, particularly among those bereaved by the virus (Torrens-Burton et al, 2021). Consistent with these challenges, around a half of people reported high/fairly high needs for help with 'loneliness and isolation', 'feeling comforted and reassured', 'finding balance between grieving and other areas of life' and 'regaining sense of purpose and meaning in life' (Harrop et al, 2021a). Social isolation and loneliness were also found to be especially prevalent among people bereaved by a Covid-19 death and among bereaved partners (Selman et al, 2021a). This contrasts with results from one of the Netherland surveys, which found that satisfaction with social support did not differ between people bereaved by Covid-19 versus other types of deaths (Eisma et al, 2021).

Most participants were supported by friends and family, but 39\% reported difficulties getting this support. A quarter reported that their friends or family were unable to support them in the way that they wanted, with a fifth feeling uncomfortable asking for help. People described how they missed being able to hug their friends and family, and the difficulties they experienced talking openly about their feelings, especially over the phone or internet. A general lack of understanding and empathy within social networks was commonly perceived. Due to the widespread stress caused by the pandemic, people worried about adding to the emotional and mental health burden of friends and family, who had their own issues to deal with. People also felt that (non-bereaved) others could not understand what they were going through due to the exceptional nature of pandemic bereavement (Harrop et al, 2021a).

Bereaved people also commonly described problems relating to workplaces. These included perceived insensitivity and a lack of understanding and compassion among managers and colleagues. At a time of financial uncertainty, people were disinclined to take leave from work out of fear of losing their jobs or livelihoods. People in frontline jobs described difficulties managing their grief and working in pressured, public-facing roles, while others described the isolating effects of being furloughed or working remotely, which made it harder for them to connect with and feel supported by their colleagues (Torrens-Burton et al, 2021).

For families living together, lack of time and space during lockdowns, and periods of school closure, made it harder for them to process and find respite from their grief (Torrens-Burton et al, 2021). Although most parents felt that their children were coping well with family-based support, some reported that their children found it difficult to open up to them. Parents and guardians also described the challenges of supporting their children while also struggling with their own grief and trying to protect them (Harrop et al, 202 1b), a problem similarly observed among bereaved relatives in another UK study (Rapa et al, 2021).

Participants with children described the added strain caused to their children by school and university closures, and associated disruption to their child's daily routines and relationships. However, parents also positively described support received through schools. Some children were receiving specialist emotional support, which although helpful stopped during periods of school closure. Other parents described the more general support provided by schools and teachers. Valued 
features of this support included checking in on students during closure periods, being aware of the student's bereavement circumstances and potential problems, having informal conversations with students and their parents about their grief, and proactively offering or placing students on the 'radar' for specialist emotional support if needed (Harrop et al, 2021b).

\section{Access to bereavement and mental health services}

We found that just over half of our participants experienced high emotional support needs and vulnerability in grief. However, three quarters of these more vulnerable participants were not accessing bereavement counselling or mental health support (Harrop et al, 2021a).

So what explains this low uptake of formal support? Only $29 \%$ of people felt that they did not need bereavement service support due to sufficient support from friends and family (Harrop et al, 2021a), however $60 \%$ of people had not tried to access bereavement services. Of those who had sought support, over half experienced difficulties accessing these services. People reported a lack of appropriate support, feeling uncomfortable asking for support and being unsure if it would help them. Some felt unhappy discussing their grief over the phone or video-call. There was also a perceived need for Covid-19-specific bereavement support as well as for culturally relevant and group-specific support for those with shared experiences. People who lost elderly parents to long-term illnesses (and in some cases Covid-19) felt less entitled due to the perceived greater needs of others and the heavy demand being placed on services as a result of the pandemic. People also reported not knowing how to access bereavement service support (Harrop et al, 2021a). Relatedly, we found that only a third of bereaved people had been given information about bereavement support services, with those bereaved in non-hospice settings less likely to be given this information, suggesting a missed opportunity for provision of such information, especially in hospital and care-home settings (Selman et al, 2021a).

Around a quarter of parents described needing additional support from bereavement or mental health services for their children, but in just over a third of cases were not receiving this support. Reasons why some children and young people were not getting the support they needed included unavailability of, or delayed referrals to, mental health services due to the pandemic, long waiting times for support, not knowing how to get support, preferences for face-to-face support, and resistance from their children to receiving external support (Harrop et al, 2021b). Rapa et al (2021) report that only a tenth of relatives bereaved during the pandemic were asked about their deceased relative's relationships with children, further suggesting that important opportunities for providing families with information about child grief and support services may have been missed.

\section{Conclusions}

This synthesis of results from the Bereaved during COVID-19 study demonstrates the exceptional challenges of pandemic bereavement, including high levels of disruption to end-of-life, death and mourning practices as well as to people's social networks and usual coping mechanisms. We identified considerable needs for emotional and therapeutic support among bereaved people alongside significant difficulties in receiving and accessing support, including for their children. Across our five publications, we have made the following recommendations for improving the experiences of adults, children and young people bereaved during and following this and future pandemics.

1 Reducing the trauma associated with death experiences, through improved communication with and involvement of families (Selman et al, 2021a), safe facilitation of family visiting to healthcare settings, and, where this is not possible, connecting families and loved ones through accessible remote communication methods (Torrens-Burton et al, 2021).

2 Improving family support immediately after a death, including routinely providing opportunities to discuss patient care and the circumstances of the death, and information about locally and nationally available bereavement support for adults, children and young people (Torrens-Burton et al, 2021).

3 Greater resourcing and expansion of national and regional adult and child bereavement services, including culturally-competent support, tailored to the needs of those bereaved during the Covid-19 pandemic, and specific support for groups with shared experiences and characteristics. 
4 Implementing strategies to improve awareness of bereavement support options for adults and children and young people, including information on services, self-help resources and materials for different age groups, promoted and made available online and in community settings (Harrop et al, 2021a, 202 1b).

5 Mitigating loneliness and social isolation, including flexible support bubble arrangements for the recently bereaved when restrictions are in place and informal community-based interventions aimed at strengthening social networks, grief literacy and communication skills, with regards to children and adults (Harrop et al, 2021a, 2021b).

6 Training for school staff to have age-appropriate conversations with students around grief and bereavement, and to be able to identify when a child might need additional specialist support. During lockdown periods of school closure specialist programmes should continue for existing students (remotely if needed), while also proactively identifying and engaging with newly bereaved families who may need support (Harrop et al, 2021b).

7 Developing, promoting and adhering to guidance and best practice recommendations regarding: a) funeral options during times of social restrictions, b) supporting those administering the death of their deceased relative, and c) supporting bereaved employees (Torrens-Burton et al, 2021).

8 Providing opportunities for remembrance, greater respect and listening to those bereaved. This means recognising the potentially dehumanising and alienating consequences of death statistics and conspiracy theories in mainstream and social media; facilitating national and local initiatives which support private and public remembrance; and inclusive consultation with those recently bereaved (eg via the UK Commission on Bereavement: bereavementcommission.org.uk) to improve support for bereaved people and ensure lessons are learned for future pandemics. (TorrensBurton et al, 2021).

\section{References}

Becqué YN, van der Geugten W, van der Heide A, Korfage IJ, Pasman HRW, Onwuteaka-Philipsen BD et al (2021) Dignity reflections based on experiences of end-of-life care during the first wave of the COVID-19 pandemic: A qualitative inquiry among bereaved relatives in the Netherlands (the CO-LIVE study). Scandinavian Fournal of Caring Sciences. https://doi.org/10.1111/scs.13038

Breen LJ, Mancini VO, Lee SA, Pappalardo EA, Neimeyer RA (2021) Risk factors for dysfunctional grief and functional impairment for all causes of death during the COVID-19 pandemic: The mediating role of meaning. Death Studies.

https://doi.org/10.1080/07481 187.2021.1974666

Eisma MC, Tamminga A, Smid GE \& Boelen PA (2021) Acute grief after deaths due to COVID-19, natural causes and unnatural causes: An empirical comparison. Fournal of Affective Disorders, 278, 54-56.

https://doi.org/10.1016/j.jad.2020.09.049

Harrop E, Farnell D, Longo M, Goss S, Sutton E, Seddon $\mathrm{K}$ et al (2020) Supporting people bereaved during COVID19: Study Report 1, 27 November 2020. Cardiff University and the University of Bristol. Available at: www.covidbereavement.com (accessed 4 December 2021).

Harrop EJ, Goss S, Farnell DJ, Longo M, Byrne A, Barawi $\mathrm{K}$ et al (2021a) Support needs and barriers to accessing support: Baseline results of a mixed-methods national survey of people bereaved during the COVID-19 pandemic. Palliative Medicine. https://doi.org/10.1177/02692163211043372

Harrop E, Goss S, Longo M, Seddon K, Torrens-Burton A, Sutton E et al (2021)b Parental perspectives on the grief and support needs of children and young people bereaved during the Covid-19 pandemic: qualitative findings from a national survey. medRxiv 2021.12.06.21267238.

https://doi.org/10.1101/2021.12.06.21267238

Hanna JR, Rapa E, Dalton LJ, Hughes R, McGlinchey T, Bennett KM et al (2021) A qualitative study of bereaved relatives' end of life experiences during the COVID-19 pandemic. Palliative Medicine, 35(5) 843-51. https://doi.org/10.1177/02692163211004210

Mayland CR, Hughes R, Lane S, McGlinchey T, Donnellan W, Bennett K et al (2021) Are public health measures and individualised care compatible in the face of a pandemic? A national observational study of bereaved relatives' experiences during the COVID-19 pandemic. Palliative Medicine.

https://doi.org/10.1177/02692163211019885

Menzies RE, Neimeyer RA, Menzies RG (2020) Death anxiety, loss, and grief in the time of COVID-19. Behaviour Change, 37(3)111-5. https://doi.org/10.1017/bec.2020.10

Neimeyer RA, Lee SA (2021) Circumstances of the death and associated risk factors for severity and impairment of COVID-19 grief. Death Studies, May 21, 1-9. https://doi.org/10.1080/07481 187.2021.1896459

Rapa E, Hanna JR, Mayland CR, Mason S, Moltrecht B \& Dalton LJ (2021) Experiences of preparing children for a death of an important adult during the COVID-19 pandemic: a mixed methods study. BMJ open. Aug 1, 11(8):e053099. https://doi.org/10.1136/bmjopen-2021053099 . 
Selman LE, Farnell DJ, Longo M, Goss S, Seddon K, Torrens-Burton A et al (2021 a) Place, cause and expectedness of death and relationship to the deceased are associated with poorer experiences of end-of-life care and challenges in early bereavement: Risk factors from an online survey of people bereaved during the COVID-19 pandemic. medRxiv.

https://doi.org/10.1101/2021.09.09.21263341

Selman E, Sowden R \& Borgstrom E (2021b) ‘Saying goodbye' during the COVID-19 pandemic: A document analysis of online newspapers with implications for end of life care. Palliative Medicine. https://doi.org/10.1177/02692163211017023.

Selman LE, Chamberlain C, Sowden R, Chao D, Selman $\mathrm{D}$, Taubert $\mathrm{M}$ et al (2021c). Sadness, despair and anger when a patient dies alone from COVID-19: A thematic content analysis of Twitter data from bereaved family members and friends. Palliative Medicine, 35(7) 12671276. https://doi.org/10.1177/02692163211017026

Sue Ryder (2020) Bereaved people claim lockdown deaths became just a statistic. Available at:

www.sueryder.org/news/bereaved-people-claim-lockdowndeaths-became-just-a-statistic (accessed 4 December 2021).

Sowden R, Borgstrom E, Selman LE (2021) 'It's like being in a war with an invisible enemy': A document analysis of bereavement due to COVID-19 in UK newspapers. PLoS one. 16(3):e0247904.
Torrens-Burton A, Goss S, Sutton E, Barawi K, Longo M, Seddon K (2021) 'It was brutal. It still is': A qualitative analysis of the challenges of bereavement during the COVID-19 pandemic reported in two national surveys. medRxiv 2021.12.06.21267354.

https://doi.org/10.1101/2021.12.06.21267354

\section{Acknowledgements}

Our thanks to everyone who completed the survey for sharing their experiences, and to all the individuals and organisations that helped disseminate the survey. We would also like to thank our research team and advisory group members for their contributions to the study.

\section{Funding}

The Bereavement during COVID-19 study is funded by the UKRI/ESRG (Grant No.

ES/V012053/1). Emily Harrop's post is supported by Marie Curie core grant funding to the Marie Curie Palliative Care Research Centre, Cardiff University (grant MCGC-FCO-11-G). 